\title{
Os dilemas da formação do professor de História no mundo contemporâneo
}

\author{
The dilemmas in the formation of History
} teachers in the contemporary world

Helenice Ciampi*

\section{Resumo}

O artigo apresenta três partes: a globalização e a educação discutindo as alterações ocorridas nas relações cotidianas; as concepções de currículos e seu significado para a formação de seus profissionais; uma experiência de formação articulando os itens desenvolvidos. As considerações finais procuram encaminhar questões, na tentativa de auxiliar o debate.

Palavras-chave: ensino de História; formação de professores; currículos.

\begin{abstract}
The article presents three parts: the globalization and education, debating the changes which have occurred in the everyday relationships; the concepts of curricula and their meaning for the training of professionals; an experience of the training, articulating the items developed. The final considerations attempt to address questionings, in order to aid the debate.

Keywords: the teaching of History; training of teachers; curricula.
\end{abstract}

Acompanhando a discussão recente da lista do Grupo de Trabalho (GT) de Ensino de História e Educação da Anpuh, duas questões sobressaem: as exigências de titulação para os concursos nas universidades - doutorado em uma área específica - História ou Educação, o que parece expressar a separação/dicotomia entre o bacharelado e licenciatura, ocasionando debates sobre a questão da formação e suas especificidades, e a reforma do ensino médio, suas possibilidades e incertezas sobre uma formação aligeirada em Ciências Humanas com o desaparecimento de disciplinas e sua reorganização em áreas. Enfim, preocupações sobre os possíveis desdobramentos das reformas sobre as diretrizes curriculares nacionais dos cursos de História.

\footnotetext{
* Pontifícia Universidade Católica (PUC) de São Paulo, Departamento de História e Programas de Pós-Graduação em Educação e História. Rua Monte Alegre, 984, Perdizes. 05014-901 São Paulo - SP - Brasil. heleciampi@uol.com.br
} 
Nesse sentido, a Coordenação do GT de Ensino e Educação da Anpuh, visando constituir formas de participação coletiva nesse debate, propôs

Para a Diretoria da entidade e colegas coordenadores regionais, uma estratégia nacional para a organização de debates em torno das reformulações curriculares, que estão tomando forma no país. Pensamos que cada GT regional de Ensino de História e Educação possa organizar e promover, num prazo até março de 2013 (em datas a serem agendadas por cada uma das regionais segundo sua disponibilidade), um debate com os associados da Anpuh, com o objetivo de elaborar um documento básico expressando a visão dos membros do GT regional sobre a mesma ... e que se constitua uma estratégia democrática para a construção de um documento que possa expressar a visão da Anpuh sobre o tema. ${ }^{1}$

Sabemos que para uma reforma curricular se desenvolver a figura/ação do professor é fundamental. Isso nos remete à premissa da importância e lugar do professor e sua formação na história da educação brasileira. No meu entendimento, faz emergir um dos pontos cruciais aos cursos de formação: a questão curricular. Foi essa a abordagem escolhida para discutir a questão do lugar da formação dos professores nos cursos de História.

O artigo apresenta três partes: a globalização e a educação discutindo as alterações ocorridas nas relações cotidianas; as concepções de currículos e seu significado para a formação de seus profissionais; e uma experiência de formação articulando os itens desenvolvidos. Considerações finais buscam encaminhar questões, na tentativa de auxiliar o debate.

\section{A globalização e A edUCAÇão}

Globalização é o conceito utilizado para caracterizar a peculiaridade do tempo presente, reconhecido como a segunda modernidade, que começou a se forjar nas últimas décadas do século XX. É um termo que se entrelaça com outros conceitos e expressões: o neoliberalismo, as novas tecnologias da comunicação e o mundo da informação. Cada um envolve temas e problemas peculiares.

A globalização é uma forma de ver o mundo em que estamos. ${ }^{2}$ Provoca um abalo nos grandes eixos da arquitetura da modernidade: o papel do Estado, a estruturação da sociedade, do trabalho, da cultura e do sujeito e, 
por decorrência, apresenta desafios para a educação. Entre eles, destaco: o solapamento do discurso e das políticas de distribuição da riqueza, que sustentam os sistemas públicos de educação, pois as políticas neoliberais deslocaram a política educacional de uma incumbência do Estado para o âmbito das decisões privadas. Consequentemente, ocorre a desvalorização do sistema educativo como um fator de integração e inclusão social em favor do incremento da iniciativa privada, da ideologia que busca uma maior junção do sistema escolar ao mundo do trabalho e às necessidades da produtividade econômica, acentuando as desigualdades sociais. A volubilidade das ocupações faz que as profissões e os empregos, ao mudarem com rapidez, deixem de ser referências seguras para alcançar e manter a identidade.

Luiz Carlos de Freitas denuncia um processo em curso, empreendido por grupos empresariais que, se prosseguir, irá destruir o sistema público de educação brasileiro, como destruiu nos Estados Unidos. Isso ocorre pela privatização da gestão, acarretando a competição entre as escolas. Freitas afirma: "trata-se da lógica do capital, abrindo brechas por meio de institutos e fundações privadas em todas as esferas de governo, até mesmo no Ministério da Educação (MEC)".3

Os resultados obtidos, pelo Brasil, no Programa Internacional de Avaliação de Alunos (Pisa), na interpretação dos reformadores empresariais, os levam à defesa de profundas mudanças no sistema educacional brasileiro. Constituem uma rede bem articulada, envolvendo a cooptação de profissionais da educação e da mídia para respaldar suas ações. Os reformadores empresariais possuem representantes em equipes governamentais interferindo diretamente nas políticas públicas de educação. ${ }^{4}$

Freitas destrói o discurso dos empresários argumentando que nos Estados Unidos, onde essas políticas vigoram há três décadas, a qualidade de ensino permanece congelada e o sistema público de educação americano foi destruído e aberto à privatização desenfreada. É a chamada privatização por concessão.

Freitas afirma: "É o público gerenciado pelo privado, mas mantida sua condição de público e de gratuidade para o aluno. É uma administração por contrato de gestão, então é a gestão da escola pública que está sendo privatizada, um caminho de privatização aberto por meio de políticas dos reformadores empresariais" (Freitas, 2012, p.10). E explicita que há um número imenso de consultores envolvidos nas secretarias e escolas. Não se realizou a melhoria 
da qualidade educacional pretendida, mas produziu-se muito lucro. O pacote inclui também a desqualificação do professor e o apostilamento das redes de ensino. Não entendem o professor como um profissional, mas como um instrutor, um 'tarefeiro'. "O suficiente é ter uma pessoa movida a bônus e uma apostila” completa o autor.

No mais, o próprio Conselho Nacional da Educação oficializou agora o que chama de Arranjo de Desenvolvimento Educacional (ADE). E esses arranjos permitem que conjuntos de municípios se articulem por recursos provenientes da iniciativa privada e do Estado ... [No Brasil], o caso mais desenvolvido que conheço é do estado de São Paulo, onde um conjunto de fundações se organizou para 'dar de presente' à Secretaria de Educação do Estado de São Paulo a consultoria da McKinsey \& Company, uma consultoria internacional que opera em mais de 140 países, em várias áreas, inclusive a educacional, e hoje está dentro da Secretaria organizando a política educacional, com pagamento feito por meia dúzia de fundações privadas brasileiras. Então você nota que começam a se estabelecer relações bem próximas entre financiamento privado, doações e o poder público, que aqui no Brasil ainda não se desenvolveu na mesma amplitude que nos EUA. (Freitas, 2012, p.12)

Considerando o mundo globalizado e a importância da tecnologia, a antropóloga argentina Paula Sibilia avalia o impacto das mídias eletrônicas no aprendizado num mundo dispersivo e refratário à reflexão. No artigo intitulado "Escola troca formação de cidadão pela capacitação de clientes", publicado na Folha de S. Paulo (7 out. 2012), afirma que o Estado perdeu capacidade de dar coesão às instituições modernas e a escola, como hoje a conhecemos, pode desaparecer.

Isso ocorre porque o eixo da subjetividade está sendo deslocado. Não mais o interior, "mas o que se vê". Daí a proliferação das redes sociais, assim como dos reality shows. A escola hoje, segundo ela, destina-se a formar "mão de obra para a sociedade industrial e bons cidadãos". Entretanto, há, segundo a autora, uma incompatibilidade entre a 'velha' instituição - a escola - e a criança e o jovem de hoje, agravada pela popularização dos dispositivos móveis de conexão às redes informáticas. Paralelamente, o espírito empresarial vai impregnando todas as instituições da sociedade. 
A autora enfatiza que as novas tecnologias não resolverão por si só o problema da escola, podendo até mesmo acentuá-lo. A informatização das aulas é apenas o primeiro passo.

Há o risco de que os aparelhos se convertam num novo agente de dispersão ... É preciso ter um projeto pedagógico realmente inovador, capaz de reconcentrar a atenção dos alunos na aprendizagem - que continuará a ocorrer prioritariamente entre as paredes da sala de aula. Tudo isso parece conspirar contra a plena consumação da vida em rede ... Na escola deveríamos aprender a pensar. Não a usar as tecnologias, ou não somente isso. Mas ensinar a pensar é muito mais difícil e tem pouco a ver com a informação e com a opinião, dois ingredientes que saturam nosso cotidiano e que imperam nas redes. Ao contrário, para poder pensar hoje é preciso cultivar certa capacidade de resistir ao fluxo constante de informações e às conexões intermitentes. Sem procurar bloqueá-las ou se isolar, mas também sem sucumbir à dispersão promovida pelas infinitas distrações nem à banalidade da opinião. (Sibilia, 2012, p.6)

Tais considerações reforçam a intenção de pensar o currículo como peça central para a formação dos professores nos cursos de História, atenta à diversidade de concepções e significados que os constituem. É o que desejo explorar no próximo item, com a análise de dois estudiosos do currículo: Thomas Popkewitz e Ivo Goodson. Eles ajudam a entender o contexto atual aqui comentado e sugerem pistas para enfrentá-lo.

\section{Perspectivas do CURRÍculo}

Thomas Popkewitz, ${ }^{5}$ professor do Departamento de Currículo e Ensino da Universidade de Wisconsin-Madison nos Estados Unidos, tem graduação em História. Em sua tese de doutorado, articula a questão do currículo com a sociologia do conhecimento em um contexto das ciências políticas, intersecção esta que o levou a reconhecer a importância de uma ciência social da escolarização, a qual tem caráter histórico.

Sua investigação interdisciplinar o levou a problematizar e compreender as questões de mudança e poder presentes no processo de escolarização. Reformas, currículos e formação de professores são entendidos como construções realizadas com base em disputas e relações de poder. Interessa entender 
de que maneira determinados processos de organização formal das práticas sociais se estruturam como um discurso capaz de produzir uma ordem institucional, mas também capacidades e desejos individuais. Nesse sentido, o conhecimento configurado no currículo é entendido como prática social e política.

O autor trabalha com o conceito de regulação social para nomear os elementos ativos de poder presentes nas capacidades individuais socialmente produzidas e disciplinadas. As reformas, para ele, constituem mecanismos de ajuste dos processos pedagógicos às demandas sociais, políticas e econômicas da sociedade em transformação.

$\mathrm{Na}$ análise das reformas educacionais de 1960 e de 1980 nos Estados Unidos, utiliza-se do conceito de epistemologia social, que fundamenta as reformas contemporâneas relacionadas às transformações tecnológicas, políticas e econômicas. $\mathrm{O}$ autor busca enfatizar a importância da compreensão das relações estruturais e da história no estudo da escolarização contemporânea e, para tal, a epistemologia torna-se fundamental na definição de como o poder atua nas instituições. Ressalta a implicação relacional e social do conhecimento.

As mudanças econômicas impulsionam as reformas educacionais para a formação de mão de obra numa economia interligada à ciência e à tecnologia, acentuadamente marcada pelo sentido pragmático e competitivo: “A crença geral no mercado como elemento de equilíbrio e eficiência social acaba sendo assimilada pela própria educação, tornando-a palco de uma crescente vinculação com a racionalidade instrumental". ${ }^{6}$

A proposta de Popkewitz concebe um mundo socialmente construído e o raciocínio como fundamental para a mudança social. Reconhece a autonomia do sujeito e, consequentemente, do professor, como agente no processo educacional e transformador da realidade. Entretanto, o papel do sujeito, e o da burocracia escolar como central na construção desse poder, são relativizados. A noção de regulação social o auxilia a "analisar as formas especificas e regionais através das quais o poder afeta e produz relações sociais". ${ }^{7}$ Porém, a perspectiva histórica dos estudos do autor centra-se menos na ação dos sujeitos e mais nas regras e padrões discursivos que 'produzem' os sujeitos. Enfim, o currículo é compreendido como "Uma imposição do conhecimento do 'eu' e do mundo que propicia ordem e disciplina aos indivíduos. Não há imposição 
através da força bruta, mas através da inscrição de sistemas simbólicos de acordo com os quais a pessoa deve interpretar e organizar o mundo e nele agir". ${ }^{8}$

As políticas estatais de centralização para garantir a qualidade do ensino estão ligadas às práticas descentralizadoras que atribuem às coletividades um papel maior no processo de decisão. As práticas centralizadoras encarnam a ideia do contrato social, em que o Estado governa para o bem-estar coletivo. As práticas descentralizadoras expressam a ideia de parceria e exigem que o contrato político seja elaborado por indivíduos e grupos autorregidos. O contato social e a parceria são analiticamente distintos. Juntos constituem uma fórmula para governar a criança e o docente.

O anglo saxão Ivor Goodson é professor de Educação na Watner Graduate School of Educacion da University of Rochester, e responsável pela cadeira de Educação na University of East Anglia, na Inglaterra. Para ele, o conhecimento é uma construção social que expressa os padrões de status e de hierarquias sociais existentes. O autor interessa-se pelo que o currículo inclui e também pelo que exclui, pois o entende como parte de um processo de aprendizagem social mais global, inseparável de questões relativas aos privilégios e à opressão. ${ }^{9}$ Coloca-se entre aqueles que estudam o currículo numa perspectiva política para focar os aspectos gerais das dinâmicas culturais, de modo a explicarem as desigualdades educativas. Segundo ele, os professores que não levam a sério os conhecimentos 'desvalorizados', 'descartados' pela noosfera, tornam-se agentes transformadores que, ao ajudarem os indivíduos a reconhecerem a sua opressão ou a cumplicidade com essa opressão, alertam a comunidade para os perigos da sua própria memória.

Os professores críticos trabalham no sentido de expor memórias incômodas que implicam recordação do modo como a consciência de vários grupos e indivíduos foi construída. Essa consciência liberta os alunos, os professores e os membros da comunidade, no sentido em que lhes permite reclamar uma identidade distinta da que lhes foi imposta. (Kincheloe, 2001, p.15)

Na sua complexidade e ambiguidade, o poder é desenvolvido tanto pelos indivíduos e grupos dominantes como pelos dominados. O autor entende que os corpos de conhecimento disciplinar, formulados para regular o público, nunca terminam completamente a sua tarefa: 
Os indivíduos e grupos-alvo não se tornam tão submissos como os que exercem o poder gostariam, ou como os analistas políticos teorizam. Goodson apercebe-se de que, embora nem todo o comportamento de oposição seja emancipatório, o processo de dominação, ao suscitar quer aquiescência quer resistência, é um campo que exige um estudo sério ... Os seres humanos são agentes ativos que trazem para os espaços disciplinares as suas identidades e capacidades, construídas ao longo da sua história de vida, muitas vezes fora de contextos regulares. Assim, os blocos de poder não possuem a capacidade de hegemonizar a paisagem cultural e de consolidar seus interesses com uma perfeição irrepreensível ... A questão é que os macroprocessos necessitam de ser analisados em nível particular. (Kincheloe, 2001, p.24-25)

O autor enfatiza que os docentes foram cada vez mais controlados pelos exames, inspeções, manuais obrigatórios e pela formação dos professores. Nesse contexto, os praticantes perderam muito do seu poder para definirem a sua prática, pois os administradores e especialistas, distantes do cotidiano escolar, ditaram as normas. É fundamental entender esses padrões de poder para haver o desenvolvimento de uma educação emancipatória e poderosa. Para Goodson, a maneira como a subjetividade é construída é um elemento central de estudo para os historiadores e outros investigadores interessados no processo pelo qual o poder influencia a atividade educacional e a formação da consciência.

O novo paradigma historiográfico do autor procura deslocar o diálogo entre o passado e o presente para um nível mais sutil, mas que envolve a aquisição de um entendimento crítico sobre as situações existentes e uma sensibilidade aos valores historicamente incrustados nessas realidades presentes. Nesse sentido, o paradigma de Goodson abarca a multidimensionalidade da relação entre práticas curriculares passadas e presentes.

Enfim, o currículo deve ser entendido não apenas como expressão, representação ou reflexo dos interesses sociais determinados, mas também como produtor de identidades e subjetividades sociais determinadas.

Nesse sentido, explicitar princípios e ações de uma prática pedagógica alimenta a discussão em pauta. Sabemos que as pesquisas na área educacional não implicam sua incorporação às práticas. A intenção é acompanhar o movimento nessa direção. 


\section{PRINCÍPIOS PARA A FORMAÇÃO DE UMA PRÁTICA OU RELAÇÃO ENTRE FORMAÇÃO E O ENSINO DE HISTÓRIA}

Um trabalho de formação de professores, que enfrente devidamente os desafios diante dessa educação globalizada e neoliberal, não passa pela negação desse processo, mas por entender a educação nesse processo. Nesse sentido, o conceito de hibridação é uma forma de enfrentar a questão. Projetos de formação de professores de algumas universidades estão atentos a esse processo. No meu contexto de trabalho, na PUC/SP, procuro efetivar essa proposta com diferentes projetos.

Em função das exigências legais, a Lei 9.394/1996, estabelecendo as Diretrizes e Bases da Educação Nacional e as Diretrizes Curriculares para os cursos de Graduação, mais especificamente o Parecer CNE/CP no 01/2002, ${ }^{10}$ levou a PUC/SP a debater uma política de graduação, desenvolvendo uma discussão acadêmica para a definição de um Projeto Institucional para a Formação de Professores da Educação Básica (PIFPEB).

Esse Projeto Institucional, votado pelo Conselho de Ensino e Pesquisa (Cepe), entrou em vigor em 2006. Entre os seus pressupostos, destaco: $1^{\circ}$ ) a prática da pesquisa, voltada às problemáticas do processo de ensino-aprendizagem e às demandas da realidade escolar, norteadora da formação profissional e da organização interna dos cursos; $2^{\circ}$ ) a articulação entre as áreas de conhecimento, no interior de projetos de atividades e pesquisas comuns entre diferentes áreas. Entre os princípios gerais do Projeto Institucional, menciono: compromisso com a prática educativa da escola pública, como referência para o desenvolvimento das atividades curriculares na formação inicial graduada e na educação continuada do professor; concepção de aprendizagem como processo de construção de conhecimentos e o desenvolvimento do pensamento autônomo, crítico e ético, como condição para a mudança de concepções, valores, atitudes, crenças e ações. ${ }^{11}$

Assume-se neste Projeto, como eixo articulador entre ensino, pesquisa e extensão, o desenvolvimento de práticas de pesquisa inerentes aos objetos de estudo dos cursos de Licenciatura e adequadas à formação profissional de professores. A operacionalidade das práticas de pesquisa nesses moldes dar-se-á no âmbito dos projetos pedagógicos de cada curso de Licenciatura. (Projeto Institucional..., 2004, p.15) 
Sabendo da distância entre o currículo prescrito, o real e o 'em ação', das dificuldades de maior integração e discussão entre os profissionais que constituem o colegiado de um curso, a formação de professores apresenta-se como um espaço privilegiado e promissor para o questionamento de tradições de ensino arraigadas e para o desenho de soluções criativas que a realidade presente parece exigir: "Privilegiado porque é o espaço possível do diálogo construtivo entre o saber acadêmico - produzido com o rigor da disciplina, mas por vezes dissociado das necessidades sociais mais urgentes e concretas - e o universo de problemas e possibilidades colocadas pelo ensino fundamental e médio". ${ }^{12}$

As discussões sobre a formação de professores têm expressado a preocupação em contemplar as imbricações do trabalho pedagógico no contexto de sua prática, para poder repensar a própria formação desses profissionais.

Em diferentes contextos institucionais de formação de professores, as preocupações se apresentam de maneira semelhante, como é o caso da USP.

A formação de professores deve partir da noção de que a docência não se realiza num quadro abstrato de relações individualizadas de ensino e aprendizagem, mas dentro de um complexo contexto social e institucional. As instituições escolares, embora em constante e forte diálogo com outras instituições, têm história, valores, saberes e práticas que lhes são específicos e, nesse sentido, têm um papel social peculiar. Não raramente, essa especificidade tem sido obscurecida pela incorporação e transposição acrítica de teorias, conceitos, e perspectivas forjados a partir de interesses alheios à educação enquanto um direito público. Esse o caso, por exemplo, da recente difusão de ideias e conceitos oriundos de teorias da administração empresarial, como, por exemplo, 'qualidade total', 'cliente,' veiculados de forma imediata e mecânica em discursos educacionais. Nesse, como em tantos outros casos análogos, a especificidade das relações, dos problemas, valores e das práticas sociais que historicamente caracterizam as instituições escolares não tem sido suficientemente reconhecida e problematizada. Importa, pois, que os princípios que norteiam a formação de professores se afastem da simples transposição, voltando-se para a análise das peculiaridades históricas dessas instituições, de seus agentes sociais e tarefas específicas de seus profissionais. Uma política de formação de professores comprometida com os problemas escolares contemporâneos deve centrar-se num esforço de compreensão das teorias, das práticas dos valores e da história das instituições escolares e seus agentes institu- 
cionais, tendo em vista que as escolas são entidades concretas em que os futuros professores exercerão suas atividades. ${ }^{13}$

Pensar em ensino significa pensar em políticas de formação de professores, e, consequentemente, nos compromissos do historiador em suas várias dimensões. Com base nos princípios e preocupações colocados pelo PIFPEB da PUC/SP, tenho procurado, nas disciplinas que leciono, desenvolver projetos de intervenção variados. Nesse contexto, emergiu a intenção de registrar as memórias, práticas e saberes de professores de História para, conjuntamente, repensar a formação do profissional dessa disciplina. Privilegiamos recortes da memória social dos docentes entrevistados, pois o senso de historicidade é formado com referências que extrapolam a universidade e o conhecimento sistematizado, implicando um campo social que coloca em destaque a força de outros processos, lugares e agentes sociais.

O objeto de estudo nesse projeto foram as memórias e práticas de professores de História, buscando centrar a reflexão sobre o processo de constituição dos saberes docentes e sua relação com o saber escolar enquanto um saber de configuração cognitiva própria e original da cultura escolar; no caso específico, 'o saber histórico escolar construído pelos professores de História de algumas Escolas Municipais da cidade de São Paulo'.

Nossa hipótese de trabalho era que os dados, coletados sobre os profissionais pesquisados, pudessem oferecer 'vestígios' sobre as marcas deixadas pela formação acadêmica e suas articulações com a cultura escolar, experiências de vida pessoal e práticas cotidianas. Procurava-se entender por que esses profissionais ensinam o que ensinam. Como redimensionam os conhecimentos e a cultura escolar? Como justificam a sua prática?

O projeto tinha como objetivos registrar memórias e práticas de professores de História da rede pública municipal da cidade de São Paulo, das séries finais do Ensino Fundamental ( $5^{\mathrm{a}}$ a $8^{\mathrm{a}}$ ), tendo, como pesquisadores, alunos da graduação, licenciatura em História; propiciar via estágio supervisionado e/ou elaboração do TCC, 'um espaço para o exercício da pesquisa', troca de experiências e diálogo entre o aluno universitário e o profissional de História da rede municipal de ensino. 
Esse projeto teve parceria com o Museu da Pessoa ${ }^{14}$ e, desenvolvido de 2005 a 2009, envolveu quarenta estagiários, entrevistando 26 professores da rede municipal de ensino.

Tenho concentrado esforços para enfrentar os desafios que a globalização coloca para a educação, e seus desdobramentos na formação de profissionais de História. O foco central é discutir a diversidade cultural existente na escola. Esta tem se organizado para discutir a diversidade social, cultural e étnico-racial de seus alunos? A questão da hibridização cultural me parece um bom caminho.

Nestor Garcia Canclini entende por hibridação processos socioculturais nos quais estruturas ou práticas discretas, que existiam de forma separada, se combinam para gerar novas estruturas, objetos e práticas. ${ }^{15}$ A construção linguística e social desse conceito permitiu sair dos discursos biológicos e essencialistas da identidade, da pureza cultural, e pensar como os estudos sobre hibridação modificaram o modo de falar sobre identidade, cultura, diferença, desigualdade, multiculturalismo e sobre pares organizadores dos conflitos nas ciências sociais: tradição-modernidade, antigo-novo, local-global.

O autor esclarece que hibridação não é sinônimo de fusão sem contradições, mas sim um possível auxílio para dar conta das formas particulares de conflito geradas na interculturalidade recente, em meio à decadência de projetos nacionais de modernização na América Latina. Para ele, a modernidade latino-americana é sui generis, caracterizada pela mistura de culturas, pela proliferação de estratégias e pluralidade de temporalidades; expressão de uma história em que a modernização ocasionou poucas vezes a substituição do tradicional e do antigo. Hibridismo incorpora contatos interculturais que recebem nomes diferentes, como mestiçagem (fusões raciais ou étnicas), o sincretismo de crenças e outras misturas como o artesanal e o industrial, o culto e o popular, o escrito e o visual.

Canclini distingue três processos para explicar a hibridação: a descoleção, ou seja, a quebra e a mescla das coleções organizadas pelos sistemas culturais; a desterritorialização dos processos simbólicos; e a expansão dos gêneros impuros.

O primeiro processo, o das descoleções, refere-se às associações realizadas entre o culto e o popular, entre os estratos culturais de classes sociais diferentes e entre produções culturais aproximadas pelas tecnologias, entendidas como 
capazes de romper hierarquias, embora inaptas para dissolver as diferenças sociais. Por desterritorialização, entende a perda da relação entendida como 'natural' da cultura com os territórios geográficos e sociais e, ao mesmo tempo, certas relocalizações territoriais relativas das velhas e novas produções simbólicas. O terceiro processo refere-se à produção dos gêneros impuros, constitucionalmente híbridos, produzidos tanto pelas descoleções quanto pela desterritorialização.

Os estudos sobre identidades, que levam em conta os processos de hibridação, revelam ser impossível considerar as identidades como se elas tratassem apenas de um conjunto de traços fixos. Enfatizam um conjunto de seleção de elementos de diferentes épocas, articulados pelos grupos hegemônicos em um relato que lhes dá coerência, dramaticidade e eloquência.

Por isso, Canclini propõe deslocar o objeto de estudo da identidade para a heterogeneidade e a hibridação interculturais. Em um mundo tão interconectado, as sedimentações identitárias organizadas em conjuntos históricos mais ou menos estáveis se reestruturam em meio a conjuntos interétnicos, transclassistas e transnacionais. As diversas formas em que os membros de cada grupo se apropriam dos repertórios heterogêneos de bens e mensagens disponíveis nos circuitos transnacionais geram novos modos de segmentação dentro de uma sociedade nacional.

Nas condições de globalização atuais, ao se intensificarem as interculturalidades migratória, econômica e midiática, percebe-se que ao lado da fusão e coesão, há a confrontação e o diálogo. A hibridação, como processo de interseção e transações, é o que torna possível que a multiculturalidade evite o que tem de segregação e se converta em interculturalidade. As políticas de hibridação serviriam para trabalhar democraticamente com as divergências, para que a história não se reduza à guerra entre culturas.

Os processos globalizadores acentuam a interculturalidade moderna quando criam mercados mundiais de bens materiais, mensagens e migrantes. Os fluxos e as interações que ocorrem nesses processos diminuíram fronteiras e alfândegas, assim como a autonomia das tradições locais.

Canclini argumenta que de um mundo multicultural (justaposição de etnias ou grupos em uma cidade ou nação) passamos a outro, intercultural e globalizado. Concepções multiculturais admitem a diversidade de culturas, enfatizando sua diferença e propondo políticas relativistas de respeito, que 
frequentemente reforçam a segregação. Interculturalidade remete à confrontação, ao entrelaçamento e àquilo que sucede quando os grupos entram em relações e trocas. Ambos os termos implicam modos distintos de produção do social. Multiculturalidade supõe aceitação do heterogêneo. Interculturalidade implica reconhecer que os diferentes têm relações de negociação, conflito e empréstimos recíprocos. ${ }^{16}$

Tais colocações nos fazem pensar sobre as potencialidades do currículo de história em relação à educação para o patrimônio. O mundo no qual vivemos é o resultado de processos que se desenvolveram no passado. Os processos são testemunhados pelas marcas produzidas pelos agentes naturais e humanos, e pelas interações que deram dinâmica aos processos. O território em que nos movemos é um mundo de marcas produzidas e deixadas pelos eventos naturais e atividades dos grupos humanos.

As marcas, nos processos de produção dos conhecimentos sobre o passado, assumem um valor cognitivo de instrumentos de informação, ou valor estético, afetivo ou simbólico, ou os quatro valores juntos. Ou seja, tornam-se bens culturais, e a história tem a ver com essas marcas. ${ }^{17}$

Nessa direção, o patrimônio tem sido um tema de discussão contemplado no curso de formação de professores de História. Ao lado da discussão conceitual há o debate com profissionais que trabalham com o patrimônio material e/ou imaterial. No ano de 2011, desenvolvemos um estudo do meio com duas turmas do curso de História, no Quilombo da Fazenda Picinguaba (refúgio dos peixes) em Ubatuba. ${ }^{18}$ Ali é desenvolvido desde 2010, no Programa Mais Cultura, o Projeto "Ponto de Cultura Olhares de Dentro: Valorizando a Memória e Fortalecendo as Raízes do Quilombo da Fazenda”, promovido pelo MEC em parceria com a Secretaria de Estado da Cultura de São Paulo.

O Projeto Olhares de Dentro tem como objetivo central trabalhar junto à comunidade jovem para formar agentes culturais locais, incentivando o interesse pelos conhecimentos tradicionais da comunidade do Quilombo da Fazenda. Pretende fortalecer a identidade individual e coletiva e a autonomia quilombola, para garantir que o modo tradicional de existência não desapareça, mesmo com todos os obstáculos enfrentados. Durante os 3 anos do projeto, têm sido realizadas ações de preservação das manifestações da cultura material e imaterial da comunidade/região. Iniciaram-se com a preservação das músicas e danças e tiveram continuidade com o "Projeto Com Quantas Memórias se 
Faz uma Canção", aprovado no final de 2010. Esse projeto tem como propósito a realização de oficinas de músicas, danças dos ritmos tradicionais caiçara/ quilombola e afro-brasileiros, além da capoeira e construção de instrumentos.

Em 2011, iniciaram-se os trabalhos de preservação voltados para o artesanato local e a construção de habitações típicas, e, em 2012, ações de preservação voltadas para a agricultura tradicional, dialogando com técnicas 'modernas' como a permacultura e a agroecologia, bem como a organização do acervo reunindo gravações, depoimentos, fotografias, músicas e outros documentos de todo o trabalho desenvolvido.

Ciente de que estudo do meio e educação patrimonial são práticas distintas, desejo apenas enfocar a pertinência de um currículo aberto para a incorporação de atividades que contemplem a realidade que o aluno, futuro profissional, irá trabalhar em um mundo intercultural e globalizado. Ambos os projetos citados são maneiras diferentes de enfrentar a questão da mercantilização do oficio docente. Porém, desejo enfatizar a importância na formação do profissional de História a reflexão sobre as questões pedagógicas, ou seja, a distinção entre o saber escolar e a ciência de referência. ${ }^{19}$

Para Jean-Claude Forquin, o saber escolar tem por base a compreensão de que a educação escolar não se limita a fazer uma seleção entre o que há de disponível da cultura num dado momento histórico, mas tem a intenção de tornar, de fato, os saberes selecionados em transmissíveis e assimiláveis. Esse processo exige um trabalho de reorganização ou 'transposição didática', que dá origem a configurações cognitivas tipicamente escolares, capazes de compor uma cultura escolar sui generis, com marcas que transcendem os limites da escola. $^{20}$

Yves Chevallard ${ }^{21}$ trabalha o conceito de transposição didática de forma diferenciada. Preocupado com a dimensão didática, opera com o conceito 'saber ensinar' e 'saber ensinado' e não com o ‘saber escolar', que traz implícita a dimensão cultural. Define transposição didática como a passagem do saber acadêmico ao saber ensinado, insistindo na distinção, separação e hierarquização entre os dois saberes. Ressalta que a transposição didática inicia-se quando técnicos dos Ministérios, Secretarias e outras instâncias do poder definem, com base no saber acadêmico e por meio de um trabalho de seleção e estruturação didática, o conhecimento a ser ensinado. 
Para a análise da história ensinada, a contribuição de Chevallard precisa ser complementada e revista, de forma que a relação hierarquizada com o saber acadêmico venha a ser repensada e possibilite a compreensão da dimensão educativa em sua estruturação. É fundamental a contribuição de Develay ao trazer para a análise o conceito de prática social de referência: "atividades sociais diversas (atividades de pesquisa, de produção, de engenharia, domésticas e culturais) que podem servir de referência às atividades escolares e a partir das quais se pode examinar, no interior de uma disciplina dada, o objeto de trabalho, ou seja, o domínio empírico que constitui a base de experiência real ou simbólica sobre a qual irá se basear o ensino". ${ }^{22}$

O diálogo com o conhecimento científico é absolutamente fundamental para pensarmos a formação do professor de História. Mas é preciso compreender melhor como se dá a construção do saber escolar, que envolve a interlocução com o conhecimento científico, mas também com outros saberes que circulam no contexto cultural de referência.

Nesse sentido, o conceito de saber escolar, referenciado em pesquisadores do campo educacional da área do currículo e da história das disciplinas escolares, oferece contribuição importante para a melhor compreensão dos processos educativos. Entre os primeiros, podemos citar, além dos trabalhos de Forquin, o de Goodson e, na história das disciplinas escolares, de André Chervel e Dominique Julia. ${ }^{23}$

Chervel argumenta serem as disciplinas escolares entidades epistemológicas relativamente autônomas. Investigando a história do ensino de francês, verificou que a gramática escolar francesa foi "historicamente criada pela própria escola, na escola e para a escola” (Chervel, 1990, p.181). Quer o autor enfatizar a especificidade epistemológica do saber escolar, não mera vulgarização ou adaptações do conhecimento de referência, e, longe de ligar a história da escola ou do sistema escolar às categorias externas a ela, a história das disciplinas, dedica-se a encontrar nela própria o princípio de sua investigação: "Porque são criações espontâneas e originais é que as disciplinas merecem um interesse todo especial" (Chervel, 1990, p.181). ${ }^{24}$

Para Dominique Julia, o conceito de cultura escolar não pode ser compreendido sem a análise "das relações conflituosas ou pacíficas que ... mantém, a cada período de sua história, com o conjunto das culturas que lhe são contemporâneas". Entende a cultura escolar como "um conjunto de normas que 
definem conhecimentos a ensinar e condutas a inculcar, e um conjunto de práticas que permitem a transmissão desses conhecimentos e a incorporação desses comportamentos". Esses saberes, normas e práticas são históricos, alterando-se mediante as finalidades da educação e a cultura das sociedades humanas (Julia, 2001, p.10).

Essa perspectiva, que reconhece a especificidade epistemológica dessa construção, tem na escola o lócus por excelência; a escola deixa de ser considerada apenas local de instrução e transmissão de saberes para ser compreendida como espaço educacional, configurado e configurador de uma cultura escolar na qual se confrontam diferentes forças e interesses sociais, econômicos, políticos e culturais.

O conceito de 'transposição didática' é, pois, polêmico e questionável. Perrenoud, por exemplo, questiona-o porque em suas análises não se considera a autonomia relativa do sistema escolar. De certo modo, o conceito de 'transposição didática' trabalha a ideia de que todo saber escolar é produzido fora da escola, sendo apenas apropriado por essa instituição. A abordagem ignora a capacidade e a possibilidade da escola como criadora de cultura.

Uma alternativa para superar a insuficiência do conceito e, também, da própria denominação 'transposição didática', sugerindo algo a ser deformado, pode ser o conceito de 'mediação didática': "um processo de constituição de uma realidade através de mediações contraditórias, de relações complexas, não imediatas, com profundo senso de dialogia". ${ }^{25}$

\section{CONSIDERAÇÕES FINAIS}

Ao professor compete dominar conhecimentos relativos à sua área disciplinar, de tal forma que a interprete e comunique, segundo sua perspectiva, ao aluno a quem ensina. Paralelamente, como ser histórico, vivencia experiências marcadas pelo seu tempo e espaço, experiências forjadoras de sua trajetória familiar, pessoal, cultural e profissional. Qualquer que seja a valorização dada pelas pedagogias à ação do professor, sujeito central ou mediador do processo educativo, existem temas/conteúdos a serem redimensionados.

Os cursos de formação de professores precisam ser pensados para dar conta das demandas atuais: profissionais que dominem tanto os processos de produção do conhecimento histórico como os do conhecimento escolar. Quem 
não domina os fundamentos historiográficos e educacionais tem muitas dificuldades para construir um saber histórico escolar. Acaba refém dos livros didáticos, nos quais a 'transposição didática' já está parcialmente realizada. A formação de profissionais de História deve exprimir o desafio de articular dois campos do conhecimento: o da história e o da educação, sem discriminação, pois trabalho complexo como esse exige uma conjugação de forças que apresenta, hoje, consistência por demais frágil, independentemente dos inúmeros trabalhos e projetos realizados e em andamento.

Essa discussão é antiga, está presente desde a fundação da Anpuh, como podemos analisar nos Anais do I Simpósio de Professores de História do Ensino Superior em Marília, 1961. ${ }^{26}$ Neles, o diretor da Faculdade de Filosofia, Ciências e Letras da Universidade do Brasil, Eremildo L. Vianna, discute a constituição do currículo de História para os cursos superiores e, sobretudo, a inclusão ou não das 'matérias auxiliares' e das 'complementares' da História: "O que se quer exigir, e se deve exigir, como do professor de História, é que saiba de quem e do que se possa servir para cumprir o seu verdadeiro mister" (grifos do autor). Insiste no bom senso "para pensar que num simples curso de formação não se pode e não se deve prejudicar o conhecimento primordial” (Anais Anpuh, 1961, p.144).

No questionamento dos participantes do simpósio destaco dois: o do professor Eduardo França e o de Cecilia Westphalen. França discorda do relator quando este preconizou a pesquisa depois do ensino, pois acha "que não pode ser feito ensino válido de pesquisa sem que ao mesmo tempo se ensine aos alunos como pesquisar". E Westphalen "acha que a Faculdade de Filosofia deve, também, cuidar da formação dos pesquisadores, com o mesmo carinho que o faz com relação aos professores secundários” (Anais Anpuh, 1961, p.156).

Nesse recorte, podemos perceber que a discussão entre ensino e pesquisa na formação do profissional já estava colocada, mas de forma invertida. A prática privilegiada era a da formação do professor, e a preocupação agora era cuidar da formação do pesquisador. O debate termina com a colocação do professor Eremildo L.Vianna considerando que, na graduação, o contato dos alunos com as fontes é apenas de aprendizagem: "considera a pesquisa algo muito mais elevado". Acha, portanto, que "devemos dar ênfase aos cursos de pós-graduação, já que temos dificuldade de formar até bons professores e bons pesquisadores" (Anais Anpuh, 1961, p.157). 
Gostaria de ressaltar a posição dos dois autores discutidos na segunda parte deste texto. Popkewitz acredita que as reformas contemporâneas reeditam a dos anos 1980. Sua análise das reformas educacionais para a formação de mão de obra numa economia interligada à ciência e tecnologia, marcada pelo sentido pragmático e competitivo explica o que acontece hoje no Brasil reforçando as colocações do diretor da Faculdade de Educação da UNICAMP, com o qual iniciamos este artigo.

Os estudos de Popkewitz contribuem para pensarmos sobre o conceito de professor que as reformas historicamente ajudaram a produzir, o do atual 'instrutor' ao qual nos referimos. Sua caracterização das políticas estatais de centralização para garantir a qualidade do ensino está ligada às práticas descentralizadoras que atribuem às coletividades (indivíduos ou grupos autorregidos) papel relevante. Essas colocações explicam o que está ocorrendo no Brasil, especialmente no estado de São Paulo.

Porém, Popkewitz ressalta a importância do raciocínio para a mudança social, fazendo coro à posição da antropóloga Paula Sibilai para a solução do ensino contemporâneo. Como vimos, o conhecimento que se configura no currículo é entendido como prática social e política, e nele encontramos, paradoxalmente, a saída para o problema a ser enfrentado na formação de professores.

Goodson, por sua vez, considera os docentes que constroem seus currículos com os conhecimentos descartados e/ou desvalorizados pelos reformadores como agentes transformadores. No limite de suas práticas, alimentam nossa positividade para o enfretamento da situação.

Nesse sentido, a iniciativa do GT de Ensino e Educação da Anpuh é um bom começo.

\section{NOTAS}

${ }^{1}$ PINTO JR., Arnaldo; MELLO, Paulo; ORIÁ, Ricardo (Coordenadores do GT de Ensino de História e Educação). Proposta de debate sobre as reformulações curriculares. (Proposal for a debate on reformulations curriculum - Coordination WG)11 abr. 2012. Disponível em: https:/groups.google.com/forum/?fromgroups\#!topic/gtensinoanpu/hf9_AsLRrU4; Acesso em: 5 jan. 2013.

${ }^{2}$ SACRISTAN, Gimeno. O significado e a função da educação na sociedade e na cultura 
globalizada. In: GARCIA, Regina Leite; MOREIRA, Antonio Flávio Barbosa (Org.). Currículo na contemporaneidade: incertezas e desafios. São Paulo: Cortez, 2003. p.41-80.

${ }^{3}$ Entrevista Luiz Freitas "Agenda dos reformadores empresariais pode destruir a educação pública no Brasil”. Revista Adusp, São Paulo, p.6-15, out. 2012.

4 "PISA, um sistema que mede o nível educacional de jovens de 15 anos por meio de provas de leitura, matemática e ciências, tem sido um dos instrumentos principais empregados por grupos de reformadores empresariais como 'Todos pela Educação' e 'Parceiros da Educação' para justificar seus projetos. O PISA é realizado pela Organização para Cooperação e Desenvolvimento Econômico (OCDE), 'herdeira do Plano Marshall', nas palavras de Freitas. O Plano Marshall foi um programa econômico de recuperação dos países europeus devastados pela Segunda Guerra Mundial, concebido e executado pelos Estados Unidos da América (EUA) a partir de 1947, e foi fundamental para a hegemonia econômica norte-americana. A OCDE, na época 'Organização para a cooperação Econômica Europeia', foi criada para coordenar o Plano Marshall” Revista Adusp, São Paulo, cit., p.7.

${ }^{5}$ POPKEWITZ, Thomas. História do currículo, regulação social e poder. In: SILVA, Tomaz Tadeu da (Org.). O sujeito da educação. Petrópolis (RJ): Vozes, 1994. p.173.

${ }^{6}$ MIRANDA, Marília Gouvêa; ROURE, Susie Amâncio Gonçalves de. Inter-Ação: Revista da Faculdade de Educação, UFG, v.27, n.2, p.1-54, jul.-dez. 2002.

${ }^{7}$ POPKEWITZ, Thomas S. Reforma educacional: uma política sociológica - poder e conhecimento em educação. Trad. Beatriz Afonso Neves. Porto Alegre: Artes médicas, 1997. p.13.

${ }^{8}$ POPKEWITZ, Thomas. Uma perspectiva comparativa das parcerias, do contrato social e dos sistemas racionais emergentes. In: TARDIF, Maurice; LESSARD, Claude (Org.). Ofício de professor: histórias, perspectivas e desafios internacionais. Petrópolis (RJ): Vozes, 2008. p.186. Ver também: CIAMPI, Helenice et al. O currículo Bandeirante. Revista Brasileira de História, São Paulo: Anpuh, v.29, n.58, p.361-382, jul.-dez. 2009.

${ }^{9}$ KINCHELOE, Joe L. Introdução. In: GOODSON, Ivor. O currículo em mudança: estudos na construção social do currículo. Porto: Porto Ed., 2001. p.7-37.

${ }^{10}$ Esse decreto instituiu as Diretrizes Curriculares Nacionais para a Formação de Professores da Educação Básica em nível superior, curso de Licenciatura de Graduação Plena.

${ }^{11}$ PROJETO Institucional para Formação de Professores da Educação Básica da PUC/SP. PIFPEB-PUC/SP, out. 2004. p.14-15.

${ }^{12}$ CRUZ, Heloisa. Projeto História, São Paulo, n.17, p.415-416, nov. 1998.

${ }^{13}$ PROGRAMA de Formação de Professores - USP, Comissão Permanente de Licenciaturas. São Paulo, 2004. p.4.

${ }^{14}$ Para este trabalho, buscamos a parceria com profissionais do Museu da Pessoa, uma organização da Sociedade Civil de Interesse Público (Oscip). Atuando desde 1991, é um museu virtual de história de vida, tendo o seu acervo disponibilizado no portal www.museudapessoa.net. 
${ }^{15}$ CANCLINI, Nestor. As culturas híbridas em tempos de globalização. Introdução à edição de 2001, p.XIX.

${ }^{16}$ CANCLINI, Nestor. Teorias da interculturalidade e fracassos políticos. Diferentes, desiguais, desconectados: mapas da interculturalidade. 2.ed. Rio de Janeiro: Ed. UFRJ, 2007. p.15-31.

${ }^{17}$ MATTOZZI, Ivo. Currículo de História e educação para o patrimônio. Educação em Revista, Belo Horizonte: Universidade Federal de Minas Gerais, Faculdade de Educação, n.47, p.135-137, jun. 2008.

${ }^{18}$ Fomos acompanhar o Projeto - Ponto de Cultura Olhares de Dentro: valorizando a Memória e fortalecendo as raízes do Quilombo da Fazenda, desenvolvido em 2010-2012 por um ex-aluno do curso de História da PUC/SP, Leonardo Estevan.

${ }^{19}$ Os comentários que se seguem foram escritos em parceria. FESTER, Helenice Ciampi Ribeiro; MONTEIRO, Ana Maria. Balanço crítico das pesquisas, tendências e demandas de investigação sobre os saberes escolares e saberes docentes no ensino de História. ENCONTRO NACIONAL DE ENSINO DE HISTÓRIA (ENPEH), 7. Lana Mara de Castro Siman e Claudia Regina Fonseca Miguel Sapag Ricci (Org.). Anais... Belo Horizonte: FAE/ UFMG, 2006.

${ }^{20}$ FORQUIN, Jean-Claude. Escola e cultura: as bases sociais e epistemológicas do conhecimento escolar. Porto Alegre: Artes Médicas Sul, 1993. p.16-17; As abordagens sociológicas do currículo: orientações teóricas e perspectivas de pesquisa. Educação e Realidade: currículo e política de identidade, Porto Alegre: Universidade Federal do Rio Grande do Sul, Faculdade de Educação, v.21, n.1, p.187-198, 1996.

${ }^{21}$ CHEVALLARD, Yves. La transposicion didática: del saber sábio al saber enseñado. Buenos Aires: Aique, s.d. Nesse trabalho, Chevallard analisa a transposição didática no âmbito do ensino da matemática.

${ }^{22}$ MONTEIRO, Ana Maria. A história ensinada: algumas configurações do saber escolar. História e Ensino: Revista do laboratório de Ensino de História, Londrina: UEL, v.9, out. 2003. p.17.

${ }^{23}$ GOODSON, Ivor. Currículo: teoria e história. Petrópolis (RJ): Vozes, 1995; CHERVEL, André. História das disciplinas escolares: reflexões sobre um campo de pesquisa. Teoria \& Educação, Porto Alegre: Pannonica, n.2, p.177-229, 1990; DOMINIQUE, Julia. Disciplinas escolares: objetivos, ensino e apropriação. In: LOPES, A. R. C.; MACEDO, E. (Org.). Disciplinas e integração curricular: história e políticas. Rio de Janeiro: DP\&A, 2002; . A cultura escolar como objeto histórico, Revista Brasileira de História da Educação, Campinas (SP), n.1, p.9-43, 2001.

${ }^{24} \mathrm{O}$ saber acadêmico nem sempre é anterior ao saber escolar. A presença das disciplinas escolares no currículo (obrigatória ou optativa), sua legitimidade, não se restringe a problemas epistemológicos ou didáticos, mas também políticos.

${ }^{25}$ LOPES, Alice Ribeiro Casimiro. Conhecimento escolar: processos de seleção cultural e 
mediação didática. Educação \& Realidade, v.22, n.1, p.95-112. jan.-jun. 1997. Na sua tese de doutoramento defendida na UFRJ, Conhecimento escolar-ciência e cotidiano (Rio de Janeiro: Ed. Uerj, 1999), Lopes amplia questões próprias da pesquisa em ensino de Ciências e Química, desejando compreender a educação como fenômeno social mais abrangente. Procura situar as constituições e características entre conhecimento escolar e saberes específicos no interior das discussões da cultura e de suas diferentes manifestações. Conclui que "o papel da epistemologia não se resume à discussão da validade epistemológica dos saberes, mas na possibilidade de introduzir uma nova forma de compreender e questionar o conhecimento, internamente, na sua própria forma de se constituir. Assim, a epistemologia contribui diretamente para a definição dos diferentes saberes sociais e de suas relações. Ao questionarmos a razão instrumental, os conhecimentos absolutizados, a unidade e universalidade da razão, não devemos desmerecer a razão, a epistemologia, a relação dialética entre objetividade e subjetividade" (p.166-167). Sugere, portanto, o conceito de 'mediação didática' para superar a insuficiência do conceito de 'transposição didática'.

${ }^{26}$ SIMPÓSIO DE PROFESSORES DE HISTÓRIA DO ENSINO SUPERIOR - ANPUH, 1. Marília (SP), out. 1961. Anais... (Relatório, p.143-157).

Artigo recebido em 20 de dezembro de 2012. Aprovado em 14 de abril de 2013. 